This is a preprint of an article published in Interest Groups \& Advocacy. The final authenticated version is available online at: https://doi.org/10.1057/s41309-020-00110-z.

A read only version is freely available at: https://rdcu.be/cd6M4

\title{
Persuading the independent: Understanding why interest groups engage with EU agencies
}

\begin{abstract}
What motivates interest groups to engage with European Union (EU) agencies? Authors have recently looked into the interaction between interest groups and these European regulators. This article sets out to discover new explanations for interest group behaviour and to add mechanisms to established explanatory factors by looking at this novel context for interest group literature. It employs an in-depth qualitative study using interviews with high level interest group representatives that interact with the European Food Safety Authority (EFSA). A novel finding is that interest groups, specifically business actors, are motivated by preventing reputational threats to the agency. This article therefore extends insights from bureaucratic reputation literature to interest group scholarship. Furthermore, interest groups are motivated by factors found in interest group literature such as influence on regulatory policy, gaining access to venues and appeasing their members. This article aids future research efforts in unravelling why interest groups engage with (EU) regulatory agencies.
\end{abstract}

Keywords: European Union, regulation, agency, interest group, lobbying, reputation

Author: Rik Joosen

Erasmus University Rotterdam

Department of Public Administration and Sociology

Burgemeester Oudlaan 50

3062PA Rotterdam

the Netherlands

joosen@essb.eur.nl 
Whereas researching interest group efforts towards regulators has a rich tradition in US interest group literature (Chubb, 1983; Golden, 1998; Yackee, 2019), researchers focused their attention only recently on why and how European Union (EU) regulatory agencies interact with interest groups (Arras and Braun, 2018; Pérez Durán, 2018; Beyers and Arras, 2019). This article builds on this trend by showing the other side of the coin. Rather than focussing on the agency's perspective, it explains why interest groups themselves are interested in engaging with EU agencies. This article therefore asks:

What motivates interest groups to engage with EU agencies?

This study adds to the debate on interest group behaviour and regulatory politics. Interest groups seek active engagement with EU agencies (Pérez Durán, 2018; Beyers and Arras, 2019). EU agencies are also interested in engaging with interest groups to cultivate information, capacity and reputation (Arras and Braun, 2018). It is, however, not yet empirically shown what interest groups gain in this context. The broader literature on interest groups has indicated that factors such as having influence (Beyers, Eising and Maloney, 2008; Baroni et al., 2014) and ensuring survival (Lowery, 2007) shape interest group behaviour, but has not yet shown whether and how these factors motivate them to engage with EU agencies in particular. Research on US agencies has provided factors that account for when interest groups lobby regulatory agencies such as the scope of issues, partisan affiliation, lobbyist experience and income and representing business interests (McKay, 2011; Boehmke, Gailmard and Patty, 2013). While these specific factors explain interest groups' engagement patterns, underlying mechanisms and motivators remain implicit. 
These shortcomings are addressed by qualitatively investigating why interest groups engage with an EU agency, the European Food Safety Authority (EFSA), using 18 interviews with high level interest group representatives. Much research on interest groups is quantitative and uses observational data (Beyers et al., 2014) and is hence mostly deductive. By using an alternative approach, this study offers two contributions.

Firstly, using an inductive approach to data collection and analysis, previously unobserved factors were discovered. EU agencies offer a unique context for this endeavour. A major difference with (national) regulatory agencies is the Meroni doctrine, dictating that EU agencies may not make normative policy decisions (Barbieri and Ongaro, 2008). Furthermore, many EU agencies rely on national regulators for expertise and implementation (Groenleer, Kaeding and Versluis, 2010; Heims, 2016). These two attributes limit EU agencies' authority and therefore the appeal for interest groups to influence their conduct. EU agencies are, however, gaining direct enforcement powers (Scholten and Scholten, 2017; Migliorati, 2020), develop binding guidelines for implementation (Chiti, 2013) and advise the European Commission on regulatory changes. Therefore, it is not unlikely that interest groups want to influence EU agencies. Capture theory even implies that regulators generally have a large potential to be influenced by actors they regulate (Dal Bó, 2006). It remains unclear, however, how interest groups navigate the unique characteristics of EU agencies, whether and how broad interest group motivators such as having influence (Beyers, Eising and Maloney, 2008; Baroni et al., 2014) and ensuring survival (Lowery, 2007) take shape given these limitations and whether other explanations are also relevant. This study employs the planned behaviour framework (Ajzen and Fishbein, 1977; Ajzen and Albarracín, 2007), which is unrelated to but compatible with interest group literature, to guide the data collection and analysis. This makes the results less guided by existing theoretical assumptions, limiting 
the bias towards confirming existing explanations while allowing their validity to be evaluated.

The analysis finds that interest groups are not only driven by previously established factors, but also to enhance the reputation of the agency they interact with. Reputation theory has been increasingly employed to explain (EU) agency decision-making, showing that they are guided by the need to maintain a unique reputation (Busuioc and Rimkute, 2020). The literature has, however, neglected to consider the effects of bureaucratic reputation management for interest group behaviour. The inductive approach allowed these effects to be uncovered and put into theoretical perspective.

As a second contribution, the qualitative approach allows implicit mechanisms behind explanatory factors, such as representing business interests (McKay, 2011; Boehmke, Gailmard and Patty, 2013), to be empirically observed. This paper shows not only that business interests interact with regulators, but also why; for example to monitor regulatory developments that impact their products.

This study has practical relevance as interest groups' behaviour towards EU agencies has normative implications. Agencies are increasingly expected to engage with stakeholders (Smismans, 2008), and EU agencies are found to appreciate interaction with interest groups (Arras and Braun, 2018). Academic and public suspicion is raised, however, whether bad intentions of (business) interest groups may harm the safety of regulated products (Dal Bó, 2006). Knowing interest groups' perspective and motivation to be involved with EU agencies is essential to determine how and to what extent EU agencies can safely benefit from them.

\section{Why do interest groups do what they do?}

As this research is inductive, theory was not its analytical starting point. Several theories are, however, instrumental in explaining why interest groups engage in their activities. To aid the 
discussion of the inductive results, a literature review on interest group behaviour is given below. It provides the theoretical concepts needed to put the findings into perspective. Note that these theories did not inform the data collection or analysis.

\section{Survival, members, influence and access}

The most fundamental theory on interest group conduct proposes that they are above all motivated by their survival (Lowery, 2007). Interest groups must secure certain resources to survive, as argued by resource dependence theory (Pfeffer and Salancik, 1978). Examples of these resources are access to policymakers, financial contributions and membership. Context specific explanations are however needed to determine what resources ensure survival in a particular case. For instance, groups with declining membership may lobby salient policies that increase their visibility to potential members.

Other theories on interest group behaviour focus more concretely on specific resources. Some focus on membership. Collective action theory implies that an interest organisation can only exists if it pursues the common interests of its members (Olson, 1971; Pecorino, 2015). Furthermore, it is important to ensure that membership pays off to avoid free riding. Interest groups may forgo benefits that would also help non-members and instead offer incentives that are exclusive to members (Olson, 1971), such as briefing them on upcoming changes to regulation and helping members comply, rather than decreasing the regulatory burden for the entire market.

Perhaps the most researched interest group resource is influence (Lowery, 2013), defined as when A induces, forces or compels B to do something that B would not otherwise do (Dahl, 1957). Many contributions take the notion that interest groups want to have influence as a given (Beyers, Eising and Maloney, 2008). Another literature shows the importance of opportunity structures which are defined as 'the set of characteristics of a given institution that determines the relative ability of (outside) groups to influence decision- 
making within that institution' (Princen and Kerremans, 2008, p. 1130). This approach also implies that interest groups pursue influence. Whether a group is successful, depends on characteristics of the institution it lobbies.

Furthermore, the resource exchange model (Bouwen, 2002, 2004), is based on the assumption that interest groups want to have access to policymakers. Interest groups supply scarce resources, such as expert information (Flöthe, 2019), in order to gain access. Interest group access can be defined as a group entering an arena, passing a threshold controlled by relevant gatekeepers (Binderkrantz, Pedersen and Beyers, 2017). Although access is a critical step towards influence (Bouwen, 2004), access may also be pursued for different reasons, such as gaining legitimacy.

\section{EU agency reputation as a resource for interest groups}

Following its inductive analysis, this paper finds another resource that interest groups pursue; the positive reputation of a regulatory agency. The theoretical foundations of the argument are discussed here.

Bureaucratic reputation is a set of beliefs about an organisation's capacity, intentions, history and mission that are held by relevant audiences (Carpenter and Krause, 2012). As reputation is key to an agency's autonomy and power, agencies avoid and contain threats to their reputation (Carpenter, 2010). Studies concluded that reputation is important for EU agencies, likely due to the regulatory framework they operate in. EU agencies have different levels of competence (Busuioc, 2010). Some decide on the market authorization of products, similar to EU member state and US federal agencies. Other EU agencies, however, only assess the risks of regulated products. The European Commission then determines whether the risk is acceptable and whether, for instance, safety risks weigh up against economic risks of banning a product (Roederer-Rynning and Daugbjerg, 2010). Bureaucratic reputation is key in this distribution of tasks. With a bad reputation, EU agencies' assessments of the industry's 
products may not be adopted by the European Commission. Studies have observed that EU agencies respond to these reputational threats, for instance by being increasingly transparent in their decision-making (Chiti, 2013) and by emphasizing their technical ability and independence in communication (Busuioc and Rimkute, 2020). Furthermore, studies found that EU agencies actively use interest groups to enhance their reputation (Arras and Braun, 2018). However, too much interest group input, especially from regulated actors, is argued to lead to regulatory capture (Dal Bó, 2006; Beyers and Arras, 2019) and may in turn diminish any reputation of expertise and independence (Rimkute, 2015). Authors observed that EU agencies have adopted strategies to deal with this dynamic (Ossege, 2015), but have failed to consider what its impact is on the interest groups themselves.

The results show that interest groups are aware of EFSA's reputational requirements and are motivated to maintain the agency's reputation. For business interest groups, EFSA's strong reputation is an important resource. It increases the agency's authority and helps business groups foresee whether EFSA's product assessments will be adopted or overruled by the European Commission, increasing the interest groups' ability to inform members about regulatory changes. But reputation could also be used differently by interest groups. It is possible that groups use the deteriorated reputation of an agency to undermine its output. For instance, a citizen group might undermine the validity of output it opposes by alerting the European Commission to reputational threats an agency faces from having conflicts of interest with the industry.

\section{Research design, operationalisation and data}

This study has an inductive, qualitative design. Given the particular characteristics of EU agencies discussed in the introduction, it is appropriate to adopt an inductive approach as they present new research puzzles (Toshkov, 2016). Inductive analysis furthermore largely 
prevents a bias towards confirming existing explanations, in particular because data are collected through interviews and are therefore obtrusive.

The study focusses on EFSA, a typical case of an EU agency that assesses the risks of products in preparation for European Commission product approval and advises the European Commission on broader regulatory changes (Chamon, 2016). Furthermore, EFSA revised its approach to interest group engagement around the time of the interviews and invited additional interest groups to be involved (EFSA, 2016). Respondents were therefore likely thinking of whether and why the agency would be interesting for them to interact with, increasing the accessibility of the data.

The data consist of 18 semi-structured interviews with high level representatives of interest groups held between 12-04-2017 and 07-06-2017. Interviews provide access to informal processes of interest groups (Beyers et al., 2014), such as motivation, which are not possible to assess using observational data. A drawback of relying on self-reported data is, however, that respondents' answers can be strategic. Interest groups may present themselves in a more favourable light than is appropriate. Results are, therefore, only presented if a substantial number of respondents agreed. Furthermore, when respondents presented conflicting information, it is presented as such. Lastly, neutral language was used during interviews ${ }^{\mathrm{i}}$, which is found to decrease strategic responses from interest groups (Beyers et al., 2014). A pilot interview helped establish neutral wording. Many studies use observational (document) data to triangulate the interview data are improve validity. Available observational data, however, reported on behaviour and not on motivation and intention. Motivation therefore had to be assessed from interest groups' own interview responses. However, this subjectivity bias should not be overstated as respondents are argued to feel pressured to speak truthfully or at least express uncertainly as they may feel examined in an academic interview (Beyers et al., 2014). 
To select interview respondents, a sampling frame was used (Beyers et al., 2014) based on a list of registered EFSA stakeholders (EFSA, 2017), established by EFSA as part of its stakeholder strategy (EFSA, 2016). All actors on the list fit a behavioural definition of interest groups, namely: groups that engage in observable policy related activities (Baroni et al., 2014). Interest groups working on EU food regulation can apply for registered stakeholder status. This grants them institutionalized access, primarily through an annual stakeholder forum and its self-appointed stakeholder bureau. Other important venues for interest groups are EFSA's public consultations, roundtables, hearings and discussion groups. These vary in accessibility, with public consultations being the most broadly accessible. Interest groups with registered stakeholder status interact most frequently with EFSA, making them ideal to probe what motivates them to engage with EU agencies. Most of these interest groups are active on a European level. EFSA's stakeholder list does not contain firms, which are rather powerful in EU policymaking (Coen, 1998), but contains mostly larger organised interests as these are the focus for EFSA's stakeholder strategy (EFSA, 2016). Furthermore, the list does not contain those for which food safety regulation is an irregular concern. These groups may therefore be motivated by other factors then those found here. The appendix includes a comparison between the interest group type distribution of registered stakeholders and of EFSA's consultation commenters. The largest biases compared to EFSA's consultations are an overrepresentation of business and a lack of public authorities as registered stakeholders.

Interest groups were randomly selected from EFSA's stakeholder list. Stratification ensured that the sample reflects the population in terms of group type distribution. The INTEREURO codebook (Berkhout et al., 2015) was used to code group types. Of the 95 interest groups in the population, 47 were approached of which 18 gave an interview (19\% sample, $38 \%$ response rate). The reasons potential respondents gave for declining an 
interview, provide insights in the selection biases. Some indicated that their interaction with EFSA is limited and others refused due to the sensitive nature of the topic, implying that this research is limited in explaining a lack of interest group motivation and motivation in salient topics. The respondents represent 10 business associations (BA), 4 citizen groups (CG), 3 professional associations (PA) and 1 research institute (RI). This sample allows for showing some differences between business associations and citizen groups, in particular because the within-group narrative overlaps. Specific findings for professional associations and research institutes could, however, not be inferred from the data. In the Appendix, an interview methods table provides an anonymised overview of the approached and interviewed interest groups, as proposed by Bleich \& Pekkanen (2015).

To operationalise the central concept of this study, motivation, sensitising concepts (Bowen, 2006) were used. These broad categories help make sense of the data while allowing results to emerge independently from existing theories. To that aim, an empirical approach from a different literature was used; the planned behaviour framework (Ajzen and Fishbein, 1977; Ajzen, 2001). Along the lines of this framework, motivation is defined as the propensity of an actor to engage in a certain kind of behaviour. The planned behaviour framework provides a way of structurally assessing this phenomenon. It has proven useful in different empirical contexts. In particular, it is suitable for reasoned decision-making, such as the decision of politicians to use strategic plans (Desmidt and Meyfroodt, 2020) and public managers' use of performance information (Kroll, 2015). Note that reasoned does not mean rational as reasons to engage in an activity may be subjective (Ajzen, 2011) and the framework focuses on perceived rather than objective factors. Adopting the planned behaviour approach in explaining interest group's motivation is suitable as it is often understood as a reasoned strategy decision, with some highlighting interest groups' experimental and less calculated strategy considerations (Pralle, 2003). The planned 
behaviour approach allows for these subjective factors to be included. Planned behaviour consists of three constructs; attitude, subjective norm and behavioural control. Attitude relies on the expectancy-value model (Ajzen, 2001) and implies that an actor is motivated to take a course of action when the consequences of a course of action are valued positively by the actor. This model fits existing explanations from interest group literature well, as it recognizes several consequences interest groups pursue and value, such as access and influence. In the operationalisation, interest groups are motived to engage with EFSA if the consequences of their engagement are positively valued by the interest group.

Subjective norm concerns what others think of a course of action and whether an actor values their opinion. When other's concerns are valued by the actor, it acts accordingly. This factor is applicable in an interest group context as interest groups are often argued to act in accordance with other actors' expectations such as their constituency and the public at large (Flöthe and Rasmussen, 2018), but also allied interest groups (Halpin, 2011). In the context of this research, subjective norm reflects expectations interest groups' outside actors have concerning their engagement with EFSA and whether interest groups comply with these expectations.

The final construct, behavioural control, concerns whether the actor has the ability to engage in a course of action. It consists of two parts; the capacity and the autonomy of an actor to do something (Yzer, 2012). Interest group research has used comparable concepts to explain interest group behaviour such as resources (Halpin, Fraussen and Nownes, 2017), comparable to capacity, and access (Binderkrantz, Pedersen and Beyers, 2017), where behaviour is not autonomous but subject to a gatekeeper's approval. In this research, behavioural control reflects the ability of an interest group to engage with EFSA, both in terms of its own capacity to do so and whether an interest groups can make the autonomous decision to engage with the agency. The latter is related to but different from subjective norm 
as subjective norm concerns the desire of an outside actor and whether that affects the motivation of a group to act. Behavioural control concerns the ability of a group to act. That ability may nonetheless be determined by an outside actor.

The broad planned behaviour framework thus allows many interest group literature concepts to be observed while allowing for undiscovered explanations of interest group behaviour to be included (see Table 1 for an overview).

[Table 1 near here]

Based on the planned behaviour approach, a topic list was made to guide the interviews and a coding scheme to analyse the data (see Appendix). The coding procedure started with the three constructs from the operationalisation and resulted in seven themes that were inductively found (see Table 2 and Appendix for full procedure).

Research using qualitative methods has received criticism for not giving transparent accounts of how research is conducted (Isaac, 2015). Especially qualitative data analysis remains difficult to report transparently. This article provides a new way of reporting qualitative analysis; empirical coverage. It combines the coverage statistic provided in NVivo qualitative coding software and the word counts of the transcripts to establish the percentage of the transcripts' word count that informed the results (see Table 2). Additionally, a percentage is given for each interview, indicating what proportion of the transcript is reported on in the results (see Appendix). This way, both the themes and the interviews can be evaluated on whether they reflect each other.

\section{Results and discussion}

[Table 2 near here]

The analysis resulted in seven inductively found subthemes for the three operationalised constructs. Most themes were discussed by a high number of respondents (see Table 2). Coverage statistics indicates the importance of topics for respondents. Most of the 
data covers attitude, followed by behavioural control and subjective norm. Most subthemes were discussed in 5 to 7 per cent of the data, except the receptiveness of the agency, which is discussed much more. Below, a description is given for each (sub)theme, supported by quotes from the interviews. Frequency counts are provided in the text to show what proportion of all respondents, or those of a certain group type, support a claim. As subthemes were not predetermined, respondents were not asked about all claims in the results. When respondents do not actively support a claim, this therefore does not mean that they oppose it. Furthermore, these inductively found results are discussed using existing theoretical accounts of interest group behaviour (see Table 2 for an overview).

\section{Attitude}

The attitude theme reflects what the positively valued consequences are of interacting with EFSA for interest groups. Taking the concept attitude as starting point, three such consequences were inductively found in the data; increasing predictability, enhancing reputation and improving risk assessment.

\section{Increasing predictability passively}

When interest groups interact with EFSA, they gain information to be better prepared, both for regulatory changes and for their future interaction with the agency. EFSA's risk assessments are particularly important for interest groups in this regard. The agency assesses the risks of food or feed substances, health claims and pesticide residues in food. EFSA bases its assessment on the dossiers of studies companies submit to apply for a market authorisation and on existing research. With EFSA's assessment, the European Commission decides whether the substance may be sold on the internal market. This decision is not only important for the company that applies for a market authorisation, but also for those that use the substance in their own products. Business associations (7/10) want to ensure that this 
regulatory system works in a predictable way and that they are not faced with surprises that negatively affect their members. A business association indicated that they observe what EFSA is doing in their risk assessments and inform their members about possible future regulatory restrictions;

'So as part of our work we do a general monitoring of any regulatory developments that might be of interest. So, we, almost on a weekly basis, we check EFSA's output for anything that might be of interest for our sector. Obviously not all of this is.' (BA9)

When EFSA gives a positive or negative assessment, the European Commission usually decides accordingly:

'And it is extremely difficult for the risk managers [European Commission or, in some contexts, national regulators] to depart from an EFSA opinion. When EFSA delivers a recommendation, then, that is the reality, the legal services of the Commission forces their services to follow the EFSA opinion. Or if they depart from it, to justify it. So, you see that way that EFSA, the panel, are much more powerful than we believe.' (BA4)

The agency has considerable informal regulatory power, making it interesting for interest groups to know what EFSA will decide in its risk assessment in order to foresee regulatory restrictions by the European Commission.

Additionally, when interest groups (8/18) engage with EFSA, they improve their abilities for future engagement. As one business association indicated about the requirements of EFSA for submitting a risk assessment request:

'It is not that we say; we don't want to do extra studies. But it is just important to companies to have a certain degree of predictability. We want to know what the requirements are.' (BA3) 
Some citizen groups (2/4) and a professional association (1/3) are also motivated to learn from interacting with EFSA. A citizen group indicated that they learn many new things through interacting with EFSA;

'And you, and to understand better what is going on. What the opportunities are with this change and what we need to ask from them. It was interesting. We had a very instructive meeting. So, we could test some things basically.' (CG4)

In their engagement with EFSA, interest groups learn more about its tactics and prepare future engagements with EFSA and the European Commission, indirectly leading to more influence. These interest groups' efforts towards EFSA are rather passive as they mostly consist of observing what EFSA does when interacting with the agency.

Survival \& membership

Given these findings, the question remains how they fit existing explanations for interest group behaviour. The observations fit well within the framework that assumes interest organisations cultivate critical resources (Pfeffer and Salancik, 1978) to secure their own survival (Lowery, 2007). In this case, they increase their ability to advocate by learning from their engagement with EFSA, as previously found by Kaya (2019) in a different context. Keeping updated on EFSA's risk assessments to inform business association members of future regulatory decisions, fits the notion of offering services that are exclusive to members. Informing members of upcoming regulation increases the appeal of business associations for (potential) members and overcomes free riding problems (Olson, 1971) as non-members will not be informed.

\section{Increasing predictability actively}

Returning to the results, respondents also indicated a more active way of increasing predictability. They aim to change the approach the agency has towards them. Many business 
associations (5/10) indicate that there is very limited interaction between a company and EFSA when its products are assessed. They indicate that EFSA behaves unpredictably, for instance by misunderstanding the dossier they submit for EFSA's risk assessment and delaying the procedure. By allowing companies to further explain complicated dossiers during risk assessment, business associations claim that the process can be made less complex and more predictable. A respondent indicated;

'If you understand the scientific thinking of the other party, it is easier to accept it. But then it goes off to EFSA. And there is no dialogue in EFSA. They don't see the full picture behind the argumentation that is being made.' (BA2)

An often-mentioned (4/18) preference of business associations is to have presubmission meetings during which a company discusses its risk assessment dossier with EFSA before it is submitted. During such a meeting, EFSA could show where the dossier needs further clarification or additional studies. Respondents indicated that they ask EFSA to implement such meetings in their interaction with the agency, but EFSA is hesitant to do so. Some interest groups (2/18) also spoke out against EFSA having such meetings during interviews, indicating that it would unduly affect the outcome of the assessment.

Influence \& access

Again, these findings fit existing theoretical frameworks well. The aim to increase predictability by increasing the interaction with EFSA is in line with the theoretical assumption that interest groups pursue both influence (Beyers, Eising and Maloney, 2008) and access (Binderkrantz, Pedersen and Beyers, 2017). In this case, some business associations want to change the agency's conduct (influence) by asking the agency to allow for more interaction (access) with companies during the risk assessment process. Respondents disagreed on whether such access in turn leads to further influence. Business associations claim that providing businesses access to risk assessments makes the process 
more predictable, with fewer delays and information requests. A citizen group and a professional association claim that industry would aim to affect the outcome of the assessment when provided access to it.

Enhancing reputation of the agency

Interest groups (10/18) are motivated to enhance and maintain the reputation of EFSA as a scientific authority. Regarding EFSA's reputation, a business association indicated that;

'It is in everybody's interest that they [EFSA] can preserve their integrity and neutrality. So that whatever they then produce as an opinion has a value.' (BA8)

And citizen groups agree:

'What our members want and what we want is to make sure that EFSA remains a reputable agency. So that we can trust their opinions. We know that if they deem that something is safe that we are sure of this. We are sure that if they approve a claim on a product, we can be confident that consumers pay for something that lives up to the expectations to what the claim says.' (CG1)

If EFSA's reputation would deteriorate, business associations (4/10) fear that the regulatory system will become based on interests rather than science. An interest group stated to want to avoid a situation where EFSA's decision making becomes politicized (BA10) as a result of threats to their reputation. Another business association indicated:

'Because for us it is of course very important that we focus on science-based decisions and legislation. And that is for us also certainly very difficult because food is something emotional and that we, the only thing that we can do is to rely on science. And otherwise it is going to get out of control, and everybody will say and decide anything, like restrictions or whatever. So, concerning that for us as well, EFSA is very important as European authority.' (BA5) 
On the other hand, citizen groups often (3/4) indicate that, despite business's seeming concerns, business associations want to influence EFSA beyond a scientific level. They indicate that:

'Industry is very interested in setting the science to its hand.' (CG4)

In order to prevent this, they address EFSA's conflicts of interest to the agency and the general public and call for a better balance in interest representation:

'I think EFSA should be more independent. I think EFSA in their process should have more the voice of consumers during the risk assessment. There is too much information from the industry. Too many conflicts of interest. And I think they can improve that. So, I believe that being, say, a stakeholder we can try to achieve this.' (CG3)

Business associations (3/10) in turn indicate that the criticism that citizen groups have, is detrimental for EFSA's reputation as it puts the agency in a bad light. Paradoxically, the efforts of citizen groups to enhance EFSA's reputation may also be detrimental to it. A citizen group indicated that the agency (unfairly) accuses them of harming their reputation:

'We are not here to undermine EFSA we are just pointing out where we see problems. And it is not, by saying it we have a bad intention or a mean hidden agenda with them. But they take that very badly. Instead of looking if they can improve, they go; "it is your fault, it is your fault we have a bad name". You know. And honestly I don't think it is an appropriate response.' (CG4)

Furthermore, the concerns from citizen groups put business representatives in a paradoxical situation. They want to maintain EFSA's reputation and avoid unpredictability, but that requires that they not interfere with the agency's work as this will lead to criticism from citizen groups. Business associations (4/10) thus claim to only address scientific inaccuracies and refrain from publicly criticising EFSA or unduly influencing the agency. 
The latter would damage EFSA's reputation and hence the predictability of the regulatory process. One interest group indicates:

'If, let's assume that we were there, going through the back door and whispering in their ears, making them write a report that would be very much matching our agenda. Then later if that was revealed, then of course the opinion [of EFSA] would have no value. So, there would be a sort of, undermining your own efforts in doing that.' (BA8)

Business associations are thus aware of the negative effects if they are too involved with EFSA. They must balance their concern for EFSA's reputation with their desire to increase their interaction during the risk assessments as indicated in the previous section. According to business associations, they often refrain from interacting with EFSA, or at least refrain from using unofficial channels or lobbying on a non-scientific basis. This is heavily contested by citizen groups which addressed their doubts about EFSA's independence from industry during the interviews.

Reputation theory

Turning to the theoretical embedding of these findings, interest groups' concerns with the reputation of their venue have not yet featured in interest group literature as something that motivates interest groups ${ }^{\text {ii }}$. This finding is puzzling as some even indicate that a strong reputation can shield an agency from interest group influence (Carpenter, 2010), which interest groups presumably want to avoid. Interest groups argue that they aim to maintain the reputation of EFSA as a scientific authority, similar to the finding that EU agencies themselves care about their reputation for technical and scientific expertise (Rimkute, 2015; Busuioc and Rimkutè, 2020). A reputation is embedded in a network of multiple audiences (Carpenter and Krause, 2012). The main audience relevant to EFSA's reputation is, according to the data, the European Commission and EU consumers (groups) who are concerned with 
food safety. When the agency has a good reputation, interest groups know that they can rely on EFSA's judgement to be respected by these audiences, in line with the theoretical assumption that reputation is instrumental to an agency's authority (Carpenter, 2010; Carpenter and Krause, 2012). Interest groups adjust their behaviour accordingly. Business associations' approach to the agency should not be suspicious as that causes the agency to lose its reputation and can no longer be counted upon to produce consequential risk assessments. Citizen groups encourage EFSA to behave more reputably by speaking out when they believe its reputation is compromised. But these actions are in itself reputational treats to the agency and may diminish the authority of EFSA in the eyes of the European Commission. This shows that the reputation of agencies, as a driver of interest group behaviour, can lead to paradoxical outcomes.

\section{Improving risk assessment}

The last subtheme of attitude is improving risk assessment. Through their interaction with EFSA, interest groups (14/18) indicate that they improve the risk assessment capabilities of the agency. They do this in two ways; by providing evidence and by improving the methodology. Interest groups provide feedback to show what they, or their members, want. Apart from data that supports their own interests, they also indicate that they give information without a particular agenda (10/18). Concerning an evaluation on the impact of pesticides on bees, a business group indicated;

'There is lots of data that can be looked at and that actually tell you a lot more. And that could help to reduce the complexity of the whole bee evaluation that is being proposed. So, it is really trying to provide science, scientific argumentation and scientific dialogue, that is what we have been trying to offer during this whole process.' (BA2).

Business associations (5/10) also indicate how products are used in order to provide a more realistic view of the risk those products pose. Additionally, interest groups (11/18) 
claim to improve the methodology for risk assessment. This is highly relevant to them as a citizen group representative indicates;

'So again, why do people engage with EFSA? That is because the devil is in the detail. And something can be dangerous or not dangerous at all, just depending on the glasses that you look with. So, if you have a methodology that allows you to reveal problems, then you will see problems. If you have a methodology that does not allow you to reveal problems, then you will not see them. And that does not mean that the problems are not there.' (CG2)

EFSA's methods determine the outcomes of their risk assessment. Hence, citizen groups (3/4) are interested in making methods more able in spotting problems and risks of products. On the other hand, business associations (3/10) indicate that they want methods to be more comprehensible for their members.

'On the fact that EFSA, in their methodology, $[x]^{\text {iii }}$ panel, its methodology, is relatively old-fashioned. And does not properly take into account [x], to meet the minimum requirement for $[x]$. That is a bit of an old-fashioned way of seeing nutrition. That is not the modern way of thinking. So that is in that sense where we see frustration.' (BA4)

Influence \& access

These results concerning changing EFSA's methodology, can be explained by the assumption in the literature that interest groups aim to influence (regulatory) policy (Beyers, Eising and Maloney, 2008; Lowery, 2013) as interest groups attempt to make EFSA do something it is currently not doing. Although, the finding that some interest groups supply data to EFSA without the aim to influence policy fits the assumption that interest groups want access to policymakers (Binderkrantz, Pedersen and Beyers, 2017) and supply resources to that effect (Bouwen, 2004). It is questionable, however, whether the information provided merely serves to gain access or also to influence the agency by providing them with 
suggestive or one-sided information. Supplying scientific data and studies may therefore also be an attempt at influence, but the interview data does not allow to infer this.

\section{Subjective norm}

In the operationalisation used, motivation is shaped by the preference of outside actors of interest groups to engage with EFSA and whether interest groups comply with these; subjective norm. Only one such outside actor was inductively found during the interviews ${ }^{\mathrm{iv}}$; the interest group's member base.

\section{Member base}

Members are highly important for interest groups. As most organisations in the sample are on a European level (16/18), members are often (13/18) national interest groups with members of their own. Some have individual members (10/18), typically firms or professionals. Interest groups in the sample $(15 / 18)$ see the common interests of their members as their most important input. A business association indicated;

'That is the starting point for me. What [the member base] thinks. And when it then happens that the EFSA assessment is in line with that, we are more than happy to use it.' (BA1)

This is more difficult for some than for others. Most business associations (6/10) represent a combination of national associations, sectorial associations and individual companies. They must combine their interests and develop expertise in many areas. Other interest groups serve a more coherent member base or even no member base at all (1/18). Disagreement between members may result in the interest group taking a more nuanced position. Business associations (4/10) indicate that they do not interfere in the competition between their members: 
'And if we would help company A, but we do not help company B and company $C$ does not at all know what to do, then we enter a competitive field. And that may not happen. And that we never do.' (BA10)

Collective action \& membership

The results on interest groups' motivation to serve their members is in line with expectations from collective action theory (Olson, 1971; Pecorino, 2015). Most tellingly, competition between members is not a collective good and hence interest group refrain from interfering. This is in line with the perspective that interest organisations exist to pursue collective goods rather than serve the individual interests of members (Olson, 1971).

\section{Behavioural control}

The final aspect of the motivation is the extent to which interest groups feel they have the capacity and autonomy to engage with EFSA: their behavioural control. Two subthemes were inductively found. The interest groups point out that their motivation to engage with EFSA is determined by their capacity in terms of scientific expertise, and by the receptiveness of the agency.

\section{Capacity}

A substantial amount of interest groups (11/18) indicate that they have limited staff and resources and therefore carefully set their priorities when it comes to engaging with EFSA:

'So, there is always a question of making a business case and whether that would be a good use of resources. Because someone needs an accommodation, to travel there, also the time that they will be taking off will run.' (BA9)

Citizen groups (2/4) expressed that their capacity is in general outweighed by the capacity of business associations. The latter can therefore arguably more easily specialise on 
the many different subjects EFSA deals with and are more capable of engaging with the agency. Many respondents (14/18) point to a specific type of capacity; scientific expertise. When interest groups have scientific expertise, in particular on toxicology and biology, they are more capable of engaging with the agency. When they do not have scientific expertise, they are often barred from interacting with EFSA. One business association indicated about cases in which EFSA asks them to provide data:

'In practice $95 \%$ of the data which are generated by our members, by the company let's say, do not meet the quality criteria of EFSA. So, they are ignored. Which means that we usually do not spend too much time in asking our members to provide data because they know that they are not taken into account by EFSA if they don't meet the minimum quality criteria.' (BA4)

And a citizen group expressed:

'You go there with a very scientific, sound proposal. "This is how the methodology should look like, because of this, this and this." You never go to EFSA with bold assessments. Because they are scientific technical people and they need data.' (CG2)

Few interest groups (2/18) indicate that their knowledge falls short of what EFSA requires. Companies, for instance, generate knowledge for in house purposes. But EFSA usually demands higher standards and ignores the data they provide. Additionally, some citizen groups and business associations (3/14) indicate that they have no scientific capacity, which prevents them from engaging with EFSA.

\section{Scientific expertise}

In line with many contributions in the literature, the results indicate that resources explain interest group motivation. Specifically, the lack of scientific knowledge demotivates interest groups to engage with EFSA as their input will likely be ignored. The concept expertise found in the literature (Gormley, 1986; Bouwen, 2002), is a similar but broader 
resource than scientific knowledge. Expertise can be both about natural scientific facts as well as the feasibly and economic impact of regulation (De Bruycker, 2016; Flöthe, 2019). The respondents indicate that EFSA favours the former. Furthermore, the effect of expertise is often seen as a marginal, linear contribution to the ability of interest groups to achieve their goals. While the results do not contradict this and respondents do indeed talk in terms of more and less expertise, the results do indicate that interest groups see scientific expertise mainly as a necessity for them to interact with EFSA. In other words, respondents discussed expertise as a dummy rather than a continuous variable, implying that is not how much but whether an interest group has scientific expertise that matters most for their motivation. This is not to say, however, that more expertise may not lead to more interest group success in the EU agency context.

\section{Receptiveness of the agency}

The final subtheme is the receptiveness of the agency towards interest groups. This is related to their autonomy to engage with EFSA; the more receptive the agency is, the more an interest groups can determine autonomously whether they engage with it. The interest groups disagree on whether the agency is too closed or open enough. Those that indicate that the agency is too closed (7/18), blame this on the criticism the agency receives for having conflicts of interest and not being independent enough:

'The problem is that in general EFSA, I suspect out of fear for more far reaching claims that they are too close to the industry, are often particularly distant, even completely distant on the level of the evaluation of scientific studies. To avoid every suspicion of conflict of interest, they rather not speak to the applicant or the owner of the [risk assessment] dossier.' (BA3)

However, the receptiveness of EFSA is not consistent. On some tasks, such as establishing broad rules on methodology and implementation of regulation, interest groups 
indicate that EFSA is much more welcoming towards them compared to specific risk assessments.

'This kind of business, when stakeholder participation is considered, so compiling guidance documents [documents that guide the implementation process], the public consultation issues, I think that we should be really happy as an industry with how this goes.' (BA3).

Primarily business associations (4/10) indicate that they are invited to provide input on these broad issues. A business association further indicated that these broader issues are more political and interest driven than the more scientific risk assessments, allowing interest groups to represent a political interest.

Furthermore, citizen groups (2/4) claim that the fact that they represent a public interest, results in the agency being more receptive towards them. They can shape public opinion and are therefore important actors to interact with for the agency. And lastly, EFSA is currently setting up a new approach towards interest group engagement. Some interest groups (3/18) indicate that this may make EFSA more open and create a better balance of interest. A citizen group indicated about this new approach:

'we think that they did a lot to meet the expectations from stakeholders when it comes to discussions when it comes to transparency, independence and stakeholder involvement.' (CG1).

But other interest groups (7/18) are hesitant and have yet to see how this new approach will turn out.

Access and venue shopping

Along the lines of the conceptualisation (Ajzen and Fishbein, 1977; Ajzen and Albarracín, 2007), an interest group's autonomy to engage with EFSA is understood to be part of its motivation to do so. The results confirm this as they show that some interest groups 
find it discouraging that EFSA is too closed towards them. This finding is in line with the definition of access, specifically the gatekeeper role of public actors (Binderkrantz, Pedersen and Beyers, 2017). It also supports venue shopping theory assumptions (Pralle, 2003; Princen and Kerremans, 2008) indicating that interest groups look at the receptiveness of a venue when deciding to advocate at certain venue.

\section{Conclusion}

This research set out to close a gap in interest group literature by explaining why interest groups are motivated to engage with EU agencies. Looking closely at interest groups interacting with EFSA, this research shows the depth and diversity of what interest groups want in this setting and how their motivation is formed. In most cases, the inductive findings fit existing theories on interest group behaviour. Interest groups are observed to strive for increased predictability, in line with the assumption that interest groups aim for survival, membership, influence and access (Olson, 1971; Lowery, 2007, 2013; Binderkrantz, Pedersen and Beyers, 2017). Furthermore, their concern for member base preferences is accounted for by collective action theory (Olson, 1971; Pecorino, 2015). The findings that interest groups' behaviour is shaped by their scientific expertise, matches resource exchange theory (Bouwen, 2002, 2004). That the receptiveness of the agency matters, fits assumptions in venue shopping theory (Princen and Kerremans, 2008) and the gatekeeper role of public actors in shaping interest group behaviour (Binderkrantz, Pedersen and Beyers, 2017). By showing why interest groups engage with EFSA, this research highlights the detailed mechanisms behind existing explanations for interest group behaviour. In the case of the reputational concerns of interest groups, however, interest group theories fall short. This paper proposes to bring in bureaucratic reputation theory to understand why interest groups are motivated to, at times, refrain from interacting with regulators. From a normative perspective, this is an important finding as EU agencies aim to build a reputation of technical 
competence (Busuioc and Rimkutè, 2020). Interest groups may be instrumental in achieving this goal as the results show they are inclined to maintain EFSA's reputation. EU agencies themselves also realise that interest groups can be used to enhance their reputation (Arras and Braun, 2018).

Looking more broadly, future research should look into how the reputation of other actors than EU agencies affect interest group conduct. Furthermore, reputation theory offers other explanations for interest group behaviour. For instance, studies recognise that interest groups themselves are also actively maintaining their public image (Chalmers and Shotton, 2016) which in turn may affect their lobby success. The results found here imply that a reputation of scientific competence may be instrumental for interest groups in influencing EU agencies. Reputation theory offers tools to investigate the nature of the reputation interest groups themselves maintain, what reputational threats interest groups face, and whether crucial audiences recognise their desired reputation (Carpenter, 2010).

The inductive nature of this study limits its generalisability. EU agencies differ in their competences and therefore in the extent to which they are interesting for interest groups to engage with. Some agencies, like the chemicals agency ECHA and the medicines agency EMA, are similar in terms of competences and should therefore have a similar appeal to interest groups. Many respondents, however, indicated that EFSA faces more reputational threats than other agencies, naming ECHA specifically. Reputational concerns might therefore be less important for other agencies. Future research should assess generalisability through a deductive study across regulatory agencies. This research, furthermore, has no empirical basis to assess whether some interest group motivators are more salient than others. Future research should study interest group behaviour to show whether they are willing, for example, to forgo influencing regulation to preserve the reputation of a regulator when it comes down to it. Researchers should also assess whether interest group conduct objectively 
contributes to or undermines the reputation of regulatory agencies using observational rather than self-reported data.

\section{Acknowledgements:}

I thank Markus Haverland and Asya Zhelyazkova for their insightful comments and guidance. I also thank two anonymous reviewers for their help in improving the paper. Furthermore, I am indebted to the interest group representatives that took the time to tell me about their work. This work was supported by the Dutch Research Council (Nederlandse Organisatie voor Wetenschappelijk Onderzoek), grant number 406.17.557.

\section{Conflict of interest statement}

The author states that there is no conflict of interest.

\section{Reference list}

Ajzen, I. (2001) 'Nature and Operation of Attitudes', Annual Review of Psychology, 52, pp. $27-58$.

Ajzen, I. (2011) 'The theory of planned behaviour: Reactions and reflections', Psychology and Health, 26(9), pp. 1113-1127.

Ajzen, I. and Albarracín, D. (2007) 'Prediction and Change Behaviour: A Reasoned Action Approach', in Ajzen, I., Albarracín, D., and Hornik, R. (eds) Predicting and Change of Health Behaviour. London: Lawrence Erlbaum Associates, pp. 3-21.

Ajzen, I. and Fishbein, M. (1977) 'Attitude-Behavior Relations: A Theoretical Analysis and Review of Empirical Research', Psychological Bulletin, 84(5), pp. 8-918.

Arras, S. and Braun, C. (2018) 'Stakeholders wanted! Why and how European Union agencies involve non-state stakeholders', Journal of European Public Policy, 25(9), pp. 1257-1275. 
Barbieri, D. and Ongaro, E. (2008) 'EU agencies: what is common and what is distinctive compared with national-level public agencies', International Review of Administrative Sciences, 74(3), pp. 395-420.

Baroni, L. et al. (2014) 'Defining and classifying interest groups', Interest Groups \& Advocacy, 3(2), pp. 141-159.

Berkhout, J. et al. (2015) 'Interest Organizations Across Economic Sectors: Explaining Interest Group Density in the European Union', Journal of European Public Policy, 22(4), pp. $462-480$.

Beyers, J. et al. (2014) 'Let's talk! On the practice and method of interviewing policy experts', Interest Groups \& Advocacy, 3(2), pp. 174-187.

Beyers, J. and Arras, S. (2019) 'Who feeds information to regulators? Stakeholder diversity in European Union regulatory agency consultations', Journal of Public Policy, 58(4), pp. $836-855$.

Beyers, J., Eising, R. and Maloney, W. (2008) 'Researching Interest Group Politics in Europe and Elsewhere: Much We Study, Little We Know?', West European Politics, 31(6), pp. $1103-1129$.

Binderkrantz, A. S., Pedersen, H. H. and Beyers, J. (2017) 'What is access? A discussion of the definition and measurement of interest group access', European Political Science, 16(3), pp. 306-319.

Bleich, E. and Pekkanen, R. J. (2015) 'Data Access, Research Transparency, and Interviews: The Interview Methods Appendix', Qualitative \& Multi-Method Research, 13(1), pp. 8-13. Boehmke, F. J., Gailmard, S. and Patty, J. W. (2013) 'Business as usual: Interest group access and representation across policy-making venues', Journal of Public Policy, 33(1), pp. $3-33$. 
Bouwen, P. (2002) 'Corporate lobbying in the European Union: The logic of access', Journal of European Public Policy, 9(3), pp. 365-390.

Bouwen, P. (2004) 'Exchanging access goods for access: A comparative study of business lobbying in the European Union institutions', European Journal of Political Research, 43(3), pp. 337-369.

Bowen, G. A. (2006) 'Grounded Theory and Sensitizing Concepts', International Journal of Qualitative Methods, 5(3), pp. 2-9.

De Bruycker, I. (2016) 'Pressure and Expertise: Explaining the Information Supply of Interest Groups in EU Legislative Lobbying', Journal of Common Market Studies, 54(3), pp. $599-616$.

Busuioc, E. M. (2010) The Accountability of European Agencies: Legal Provisions and Ongoing Practices. Delft: Eburon.

Busuioc, E. M. and Rimkutè, D. (2020) 'Meeting expectations in the EU regulatory state? Regulatory communications amid conflicting institutional demands', Journal of European Public Policy, 27(4), pp. 1-22.

Carpenter, D. P. (2010) Reputation and power : organizational image and pharmaceutical regulation at the FDA. Princeton: Princeton University Press.

Carpenter, D. P. and Krause, G. A. (2012) 'Reputation and Public Administration', Public Administration Review, 72(1), pp. 26-32.

Chalmers, A. W. and Shotton, P. A. (2016) 'Changing the Face of Advocacy? Explaining Interest Organizations' Use of Social Media Strategies', Political Communication, 33(3), pp. 374-391.

Chamon, M. (2016) 'Setting the Scene', in EU Agencies: Legal and Political Limits to the 
Transformation of the EU Administration. Oxford: Oxford University Press, pp. 4-52.

Chiti, E. (2013) 'European Agencies' Rulemaking: Powers, Procedures and Assessment', European Law Journal, 19(1), pp. 93-110.

Chubb, J. E. (1983) Interest groups and the bureaucracy: The politics of energy. Redwood City: Stanford University Press.

Coen, D. (1998) 'European business interest and the nation state: large firm lobbying in the European Union and member states', Journal of Public Policy, 18(1), pp. 75-100.

Dahl, R. A. (1957) ‘The Concept of Power’, Behavioral Science, 2(3), pp. 201-2015.

Dal Bó, E. (2006) 'Regulatory capture: A review', Oxford Review of Economic Policy, 22(2), pp. 203-225.

Desmidt, S. and Meyfroodt, K. (2020) 'What motivates politicians to use strategic plans as a decision-making tool? Insights from the theory of planned behaviour', Public Management Review, pp. 1-28.

EFSA (2016) EFSA Stakeholder Engagement Approach.

EFSA (2017) Stakeholders Registered List.

Flöthe, L. (2019) 'Technocratic or democratic interest representation? How different types of information affect lobbying success', Interest Groups \& Advocacy, 8(2), pp. 165-183.

Flöthe, L. and Rasmussen, A. (2018) 'Public voices in the heavenly chorus? Group type bias and opinion representation', Journal of European Public Policy, 26(6), pp. 1-19.

Golden, M. M. (1998) 'Interest groups in the rule-making process: Who participates? Whose voices get heard?', Journal of Public Administration Research and Theory, 8(2), pp. 245270.

Gormley, W. T. J. (1986) 'Regulatory Issue Networks in a Federal System', Polity, 18(4), pp. 
$595-620$.

Groenleer, M., Kaeding, M. and Versluis, E. (2010) 'Regulatory governance through agencies of the European Union? The role of the European agencies for maritime and aviation safety in the implementation of European transport legislation', Journal of European Public Policy, 17(8), pp. 1212-1230.

Halpin, D. R. (2011) 'Explaining Policy Bandwagons: Organized Interest Mobilization and Cascades of Attention', Governance, 24(2), pp. 205-230.

Halpin, D. R., Fraussen, B. and Nownes, A. J. (2017) 'The balancing act of establishing a policy agenda: Conceptualizing and measuring drivers of issue prioritization within interest groups', Governance, 31(2), pp. 1-23.

Heims, E. M. (2016) 'Explaining coordination between national regulators in EU agencies: The role of formal and informal social organization', Public Administration, 94(4), pp. 881896.

Isaac, J. C. (2015) 'For a More Public Political Science', Perspectives on politics, 13(2), pp. $269-283$.

Kaya, C. (2019) 'Providing information and building capacity: Interest group involvement in the application of EU law', West European Politics, 42(1), pp. 25-44.

Kroll, A. (2015) 'Explaining the Use of Performance Information by Public Managers: A Planned-Behavior Approach', American Review of Public Administration, 45(2), pp. 201215.

Lowery, D. (2007) 'Why Do Organized Interests Lobby? A Multi-Goal, Multi-Context Theory of Lobbying', Polity, 39(1), pp. 29-54.

Lowery, D. (2013) 'Lobbying influence: Meaning, measurement and missing', Interest 
Groups \& Advocacy, 2(1), pp. 1-26.

McKay, A. M. (2011) 'The decision to lobby bureaucrats', Public Choice, 147(1/2), pp. 123138.

Migliorati, M. (2020) 'Relying on agencies in major European Union legislative measures', West European Politics, 43(1), pp. 159-180.

Olson, M. (1971) The Logic of Collective Action: Public Goods and the Theory of Groups. Cambridge: Harvard University Press.

Ossege, C. (2015) 'Driven by Expertise and Insulation? The Autonomy of European Regulatory Agencies', Politics and Governance, 3(1), pp. 101-113.

Pecorino, P. (2015) 'Olson's Logic of Collective Action at fifty', Public Choice, 162(3/4), pp. $243-262$.

Pérez Durán, I. (2018) 'Interest group representation in the formal design of European Union agencies', Regulation and Governance, 12(2), pp. 238-262.

Pfeffer, J. and Salancik, G. R. (1978) The External Control of Organizations: A Resource Dependence Perspective. Stanford: Stanford Business Books.

Pralle, S. B. (2003) 'Venue shopping, political strategy, and policy change: The internationalization of Canadian Forest Advocacy', Journal of Public Policy, 23(3), pp. 233260.

Princen, S. and Kerremans, B. (2008) 'Opportunity Structures in the EU Multi-Level System', West European Politics, 31(6), pp. 1129-1146.

Rimkute, D. (2015) 'Explaining Differences in Scientific Expertise Use : The Politics of Pesticides', Politics and Governance, 3(1), pp. 114-127.

Roederer-Rynning, C. and Daugbjerg, C. (2010) 'Power learning or path dependency?: 
Investigating the roots of the European food safety authority', Public Administration, 88(2), pp. 315-330.

Scholten, M. and Scholten, D. (2017) 'From Regulation to Enforcement in the EU Policy Cycle: A New Type of Functional Spillover?', Journal of Common Market Studies, 55(4), pp. 925-942.

Smismans, S. (2008) 'New modes of governance and the participatory myth', West European Politics, 31(5), pp. 874-895.

Toshkov, D. (2016) Research Design in Political Science. London: Palgrave Macmillan.

Trapp, N. L. and Laursen, B. (2017) 'Inside out: Interest groups' "outside” media work as a means to manage "inside" lobbying efforts and relationships with politicians', Interest Groups \& Advocacy, 6(2), pp. 143-160.

Yackee, S. W. (2019) 'The Politics of Rulemaking in the United States', Annual Review of Political Science, 22, pp. 37-55.

Yzer, M. (2012) 'Perceived behavioral control in reasoned action theory: A dual-aspect interpretation', Annals of the American Academy of Political and Social Science, 640(1), pp. $101-117$. 


\section{Tables}

Table 1: Operationalisation using planned behaviour approach

\begin{tabular}{lll}
\hline Construct & Explanation of motivation & Compatible concepts \\
\hline Attitude & Consequences of engaging & Access, influence \\
& with EFSA are valued & \\
positively by the interest & \\
group & Other actors want the interest & Membership, societal \\
\hline Subjective norm & group to engage with EFSA & pressure, interest group \\
& and it complies with these & cooperation \\
\hline Behavioural control & expectations & \\
\hline Interest group has the capacity & Resources, gatekeeper \\
& and autonomy to engage with & \\
\hline
\end{tabular}


Table 2: Themes with numbers of interviews mentioning them (Frequency) and empirical coverage measures (\% total word count).

\begin{tabular}{lccc}
\hline Themes & Freq. & \% total WC & Theoretical explanation \\
\hline Attitude & 18 & 25.63 & \\
\hline - Increasing predictability & 14 & 6.05 & Survival, membership, \\
& & & influence \& access \\
\hline - Enhancing reputation & 13 & 6.83 & Reputation \\
\hline - Improving risk assessment & 14 & 5.97 & Influence, access \\
\hline Subjective norm & & & \\
\hline - Member base & 16 & 7.11 & Membership \\
\hline Behavioural control & 16 & 5.12 & \\
\hline - Capacity & 18 & 17.01 & \\
\hline - Receptiveness of the agency & 16 & 9.20 & Expertise, access \\
\hline Total subthemes & 18 & 6.88 & \\
\hline Total main themes & & 40.05 & \\
\hline
\end{tabular}




\section{Endnotes}

i Examples include 'How capable are you to make your voice heard in European policymaking?' (asked to BA1) instead of 'How influential are you?' and using the term 'stakeholder' instead of ‘interest group' for citizen groups as they are more comfortable with it.

ii See Arras \& Braun (2018) for reputational expectations of EU agencies from their engagement with interest groups and Trapp \& Laursen (2017) arguing that interest groups maintain a positive public image of policymakers through media appearances.

iii $[\mathrm{x}]$ is used instead of information that compromises the respodent's anonymity.

${ }^{\text {iv }}$ Interest groups are sometimes invited by EFSA, suggesting that the agency also wants interest groups to engage. However, for consistency with similar findings, this is discussed under behavioural control. 